\title{
Imaging industrial contaminant plumes with resistivity techniques
}

\author{
Olivar A.L. de Lima, Hédison K. Sato, Milton J. Porsani \\ PPPG/UFBA, Instituto de Geociências, Rua Caetano Moura, 123, Federação 40210, Salvador, Bahia, Brazil
}

Received 10 May 1994; accepted 18 July 1995

\begin{abstract}
A systematic geophysical procedure has been developed and applied to image groundwater contamination caused by industrial activities in Bahia, Brazil. The procedure combines the use of conventional Schlumberger sounding with a regular scheme of sampling the resistivity stratification in depth. This is achieved by traversing an area with multiple profiles measured at selected electrode spacing. By multiple profiles we mean closely spaced partial soundings made using only six electrode spacings. Partial and complete soundings are correlated and inverted assuming horizontally stratified models within the limits covered by each electrode array. Pseudo-resistivity sections constructed from these data are inverted and adjusted using a two-dimensional finite difference algorithm. Electrical and lithological well logs are used to constrain this interpretation. The procedure was successfully applied to investigate the groundwater conditions and to outline contaminant plumes within industrial areas of the Camaçari Petrochemical Center, Recôncavo basin, Bahia. The study includes cases of electrically conductive plumes generated by infiltration of inorganic aqueous effluents and a resistive plume containing hydrocarbon contaminants.
\end{abstract}

\section{Introduction}

Earth resistivity methods have been widely used to study the petrophysics and hydrological conditions of underground aquifer structures. This is feasible because electric current in rocks, although strongly controlled by the amount and salinity of the pore electrolytes, is also dependent on the tortuosity of the pore space and on the proportion of dispersed conducting solids. In fact, conventional geoelectrical techniques have been used effectively in resolving many complex problems in geohydrology and in geotechnics (Dobecki and Romig, 1985; Mazac et al., 1987, 1989).

The success of an electrical technique in locating underground contaminant plumes depends on the size and shape of the plume and the resistivity contrast between the native groundwater and the invading fluid, among other factors. Aquifer pollution caused by liquid effluents from oil and ore production and processing and by several types of industrial wastes have been detected, mapped, and modeled using resistivity methods (Busseli et al., 1990; Barker, 1990; Bauman et al., 1993). A systematic geophysical program of contamination surveys has recently been started by PPPG/ UFBA on a critical industrial area in the Recôncavo basin, Bahia, Brazil (de Lima and Porsani, 1992).

The Recôncavo basin contains an extensive multistory aquifer confined within the upper $1000 \mathrm{~m}$ of a fluvial shale/sandstone sequence known as S. Sebastião Formation. This system furnishes water for domestic use in many cities and villages in the region and is also being heavily exploited for industrial use. The installation of a large petrochemical complex near Salvador (Fig. 1) during the early 1970s has imposed a severe risk to this important resource. A detailed knowledge of the geohydrological conditions in the area is now urgently required to prevent irrepairable damage to this water supply. Organic and inorganic 


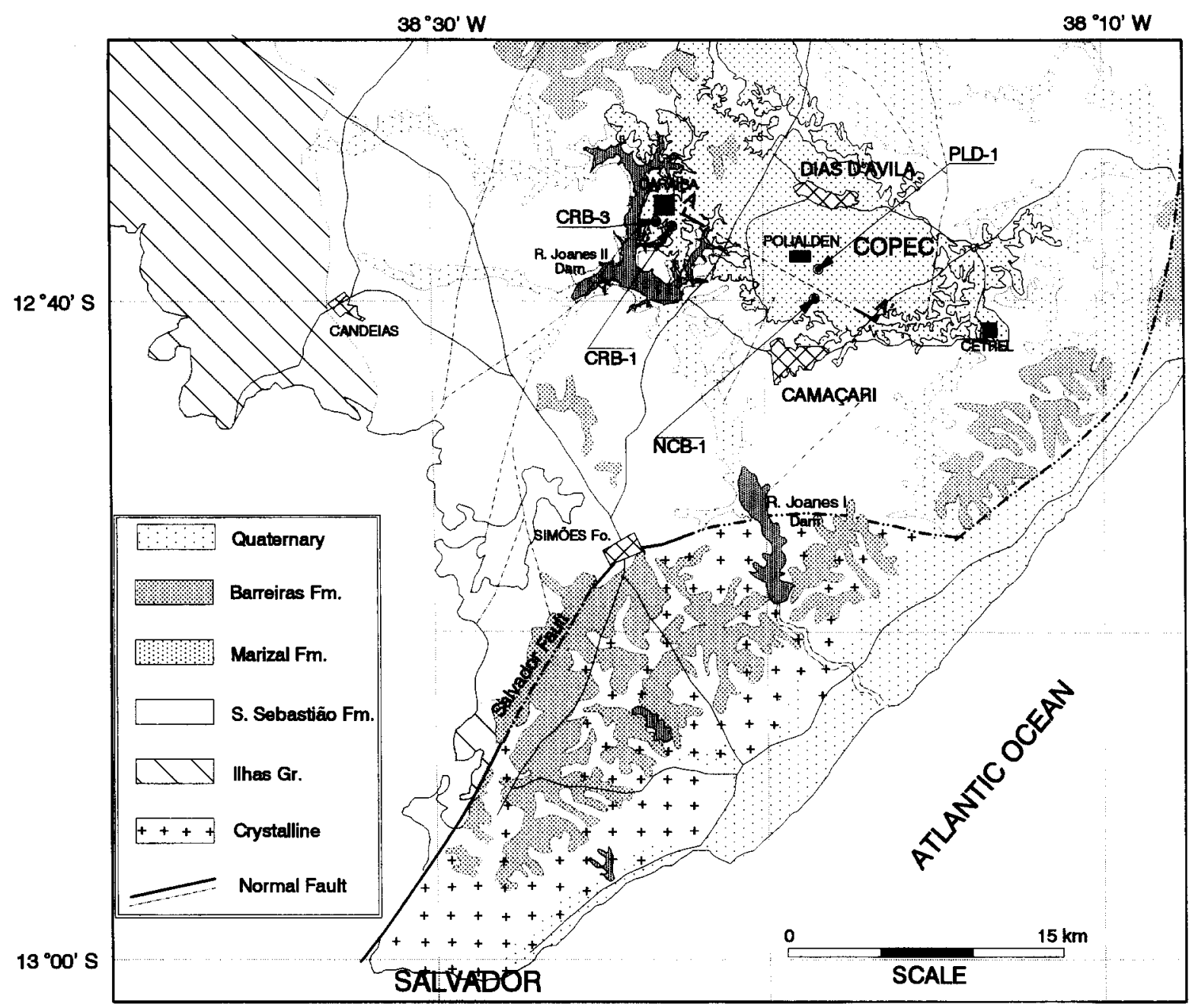

Fig. 1. Geological and location map of the study areas in the Copec center, Salvador, Bahia. Cross-section $A-A^{\prime}$ is shown in Fig. 5 .

surface disposal and many accidental spills are common in this area and there are contaminant plumes possibly invading the water-table aquifer. Such contaminations result from the raw materials, the intermediate products, and the residual liquid wastes used by this petrochemical complex (Copec).

Apart from this, another important problem affecting the groundwater resource in the Copec area is the widespread use of test borings to test or monitor suspicious underground plumes. More than 500 piezometric wells in the depth range of $10-30 \mathrm{~m}$ are reported in the area. Most of them were constructed without following strict technical norms and may be acting as new pathways for the infiltration of contaminants. Indirect non-inva- sive survey techniques offer a preferable approach to these assessment and monitoring goals.

In this work we describe the results of electrical geophysical techniques we have applied in representative areas of the Copec for the purposes of (1) delineating the structural configuration and defining the geohydrological conditions down to depths of about 50 $\mathrm{m}$, (2) inferring petrophysical characteristics and water quality of the upper aquifer layers, and (3) demonstrating the efficacy of a simple electrical resistivity procedure in distinguishing between the two basic types of contaminants, namely conductive (inorganic) and resistive (organic) plumes. 


\section{Geophysical foundations}

Geophysical identification of pollutants present in groundwater depends on the contrast between the physical properties of a porous rock when it is saturated with native groundwater and when it contains different proportions of pollutant liquids. In this sense, the electrical resistivity and the dielectric permittivity are both potentially useful in sensing such contrasts. The basic requirements for good resolution are that (1) the electrical impedance contrast must be above the experimental measurement threshold, (2) variations due to lithology must be distinguished by some other means, and (3) lateral responses caused by small subsurface heterogeneities must be identified and removed.

For this purpose, we have developed a practical geoelectrical procedure that has been shown to be very successful. It combines conventional electrical sounding with a scheme of sampling the subsurface resistivity with multiple profiling at several electrode spacings. Such multiple profiles consist of closely spaced partial electrical soundings made with a small number of sampling points. The Schlumberger array is preferred because lateral heterogeneities are well emphasized.
With this electrode array, the apparent resistivity function integrates lateral effects with weights that are inversely proportional to the squared distance from the heterogeneity to the current source (Deppermann, 1955).

Techniques using multi-electrode arrays have been used by several authors to study resistivity variations in essentially two-dimensional structures. Griffiths and Turnbull (1985), for instance, developed a multi-cable system and applied multi-profiling using a Wenner array to study the hydrogeological condition of crystalline aquifers in Zimbabwe. Medeiros and de Lima (1990) suggested a field setup and an interpreting procedure for multi-profiling using a Schlumberger array for evaluating crystalline aquifers in northeastern Brazil. The present studies have benefited from these previous efforts.

Geophysical images can be constructed as traverse pseudo-resistivity sections and apparent resistivity maps for selected array spacings. Complete and partial soundings can be correlated and inverted assuming horizontally layered models within the limits of the array depth response. The interpreted results can be calibrated and constrained by available well log data.

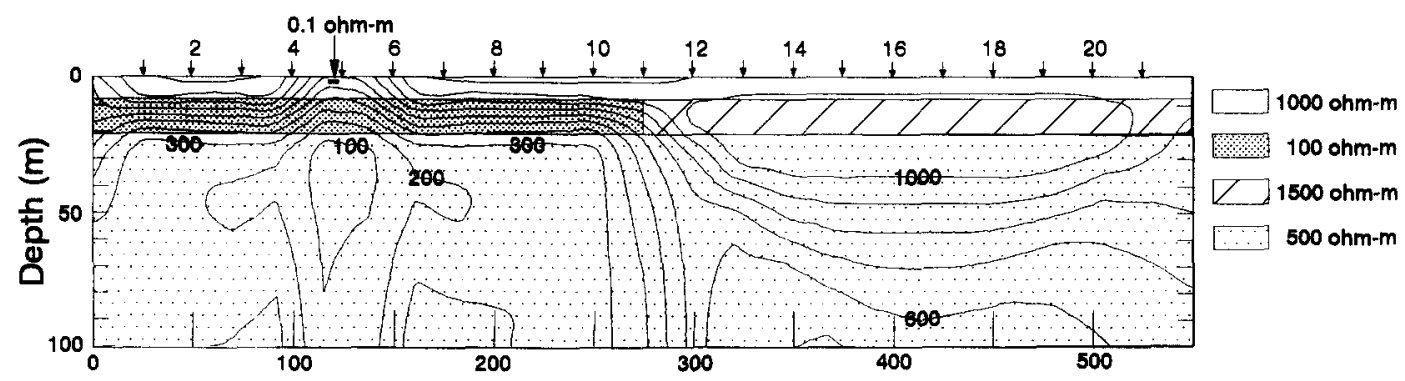

a) 2-D Initial model

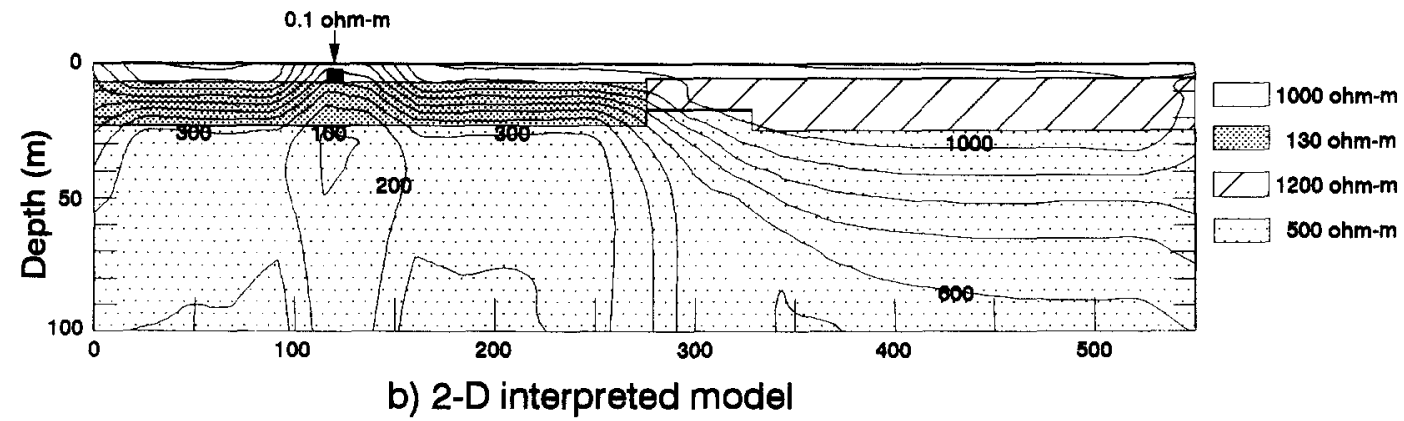

Fig. 2. Pseudo-resistivity and geoelectrical sections for a synthetic model of aquifer contamination. Arrows at the top of cross-section (a) show sounding locations. 


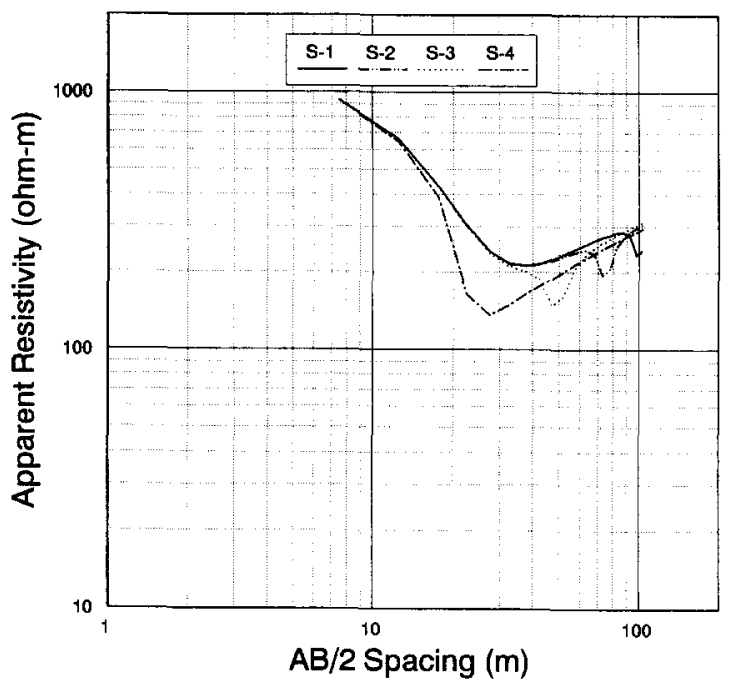

(a)

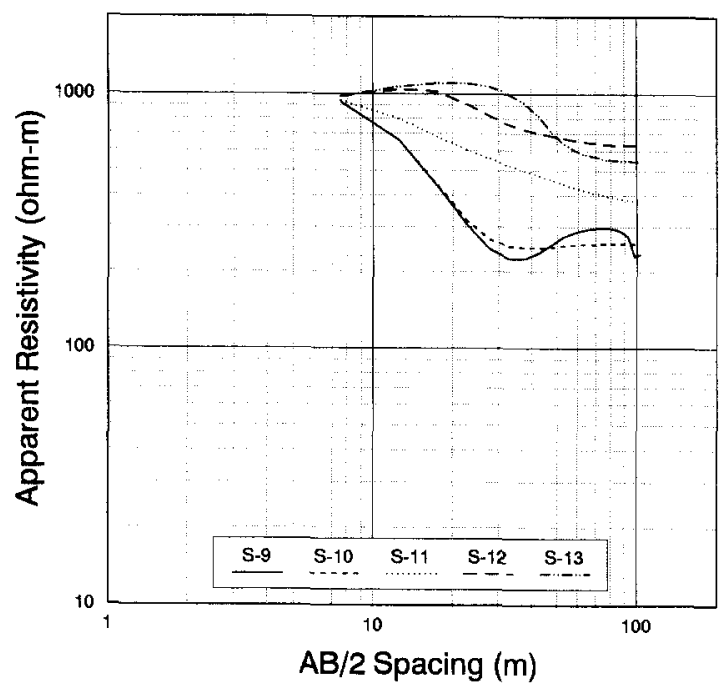

(b)

Fig. 3. Characteristic Schlumberger soundings at several numbered locations along the section of Fig. 2 .

In many instances, a contaminant plume may be oriented differently from the assumed horizontally layered condition. In general, however, it has a horizontal dimension (usually the one along the migration direction) which is larger than the others, in such a way that a two-dimensional structural approximation is satisfactory for a quantitative evaluation of the pseudo-resistivity sections.

Fig. 2 shows a synthetic two-dimensional geoelectrical model containing some of the physical features of a contaminant pattern found in the Copec area. An upper homogeneous water-table aquifer was invaded by a conductive fluid (darker fill) in such a way that two resistivity regions with a sharp vertical contact developed. A small, very conductive, linear heterogeneity is located on the left side of the vertical contact above the water level. This anomaly simulates a drainage ditch or pipe typical of the contamination source. The underlying semi-confined homogeneous aquifer extends to great depths (Fig. 2a).

A pseudo-resistivity section was contoured for this synthetic model using electrical sounding data computed by forward model analysis at the surface stations indicated on the profile. At each station, the Schlumberger array was expanded parallel to the profile direction. The distance between sounding centers was chosen to allow close delineation of resistivity changes in the model. The sounding results were computed using a finite difference code based on Dey and Morrison's (1979) algorithm.

Fig. $2 b$ shows the reconstructed structure after interpreting the sounding data under the assumed conditions and following the procedure to be discussed in a later section. It can be verified that, although we may have slight differences between the interpreted structure and the generating model, the results are considered satisfactory, particularly in view of the experimental limitations of the electric method.

A few sounding curves centered near the surficial heterogeneity and at the vertical contact interface are depicted in Fig. 3. As shown, when a current electrode approaches the conductive ditch (Fig. 3a), there is a sharp decrease in the apparent resistivity function, with a slope well above that expected for a horizontally layered Earth. After the electrode crosses the discontinuity, the apparent resistivity shows a sharp increase, this time reaching an inclination above $45^{\circ}$. In contrast to the case of horizontal stratification, the conductive V-shaped anomaly is shifted on the curves as the sounding center approaches or recedes from the ditch. Moreover, there is an almost perfect symmetry between the curves computed for the two sides of the conductor. Such features in the $\rho_{\mathrm{a}}$-curve allow the size of a lateral heterogeneity and its position to be estimated along a given profile.

Similar features are observed when approaching the vertical contact (Fig. 3b). However, the depth and ver- 
tical extent of this boundary decrease the amplitude and smooth the apparent resistivity discontinuities such that the soundings appear to be caused by horizontal stratification. However, as in the case of seismic refraction profiles, by surveying the anomaly using different sounding arrays, helps to distinguish the vertical boundary from cases of sub-horizontal layering.

\section{Practical application}

Field test areas where the above procedures have been applied are shown in Fig. 1. The first, referred to as the Cetrel area, includes a number of artificial basins constructed for the final disposal of processed sludge. Such sludges result from chemical-biological treatment of the liquid effluents from the industries of Copec. The second area (Caraiba) involves a metallurgical plant active in copper production with sulfuric acid as a by-product. The third area (Polialden) is a petrochemical industry that manufactures polyethylene fibers and other polymeric products.

\subsection{Geohydrological setting}

Copec industries are located on the top of the Bahia Supergroup, a thick sedimentary sequence that fills the Recôncavo basin. This basin is a paleorift structure developed in the Early Cretaceous, in response to the continental spreading of South America and Africa (Milani and Davison, 1988). The upper portion of this sedimentary pile corresponds to the Marizal and S. Sebastião formations (Fig. 1 ).

The Marizal Formation is a postrift association of alluvial fans and braided river deposits, including poorly-consolidated kaolinic sandstones, with massive or stratified conglomeratic bodies on its base. Locally, thin beds of shales and claystones may be present. It overlies in angular disconformity the S. Sebastião sandstones and has a thickness that does not exceed $50 \mathrm{~m}$ in the Recôncavo basin.

The S. Sebastião Formation is a thick fluvial sequence deposited by a large meandering stream, composed of thick stratified sandstones interlayered with shales, siltstones and limestones. The sandstones represent coalescent point bars whereas the shales and siltsones are floodplain deposits or the fillings of aban- doned river channels. Its thickness may reach more than $2000 \mathrm{~m}$ in the area.

Examples of induction and micro-resistivity logs from wells drilled in the area are shown in Fig. 4. These wells, drilled mainly to supply the industries, have depths between 150 and $350 \mathrm{~m}$. In Fig. 4, however, only their upper sections are being displayed to show the main lithologic features and the stratigraphical relationship between the Marizal and S. Sebastião formations.

The Marizal Formation is macroscopically represented as an almost uniformly resistive unit. However, fine-scale electrical stratification can be recognized on the micrologs, which may be attributed to lithological and textural variations within this formation. In fact, from drilling data they were identified as a sucession of shaly-sand beds, poorly sorted, coarse grained at their basis and fining upwards. Thin layers or lenses of clays were also identified. Extensive basal and interlayer silicified conglomerates, poorly-sorted and matrix supported are common. They have very small permeabilities, as can be inferred from the absence of a visual separation between the microlog curves facing them (Fig. 4).

Electrical logs were also used for estimating the porosity and clay content of the Marizal sands. This was achieved through the following procedure: (1) resistivities of the flushed $\left(R_{\mathrm{xo}}\right)$ and virgin $\left(R_{\mathrm{o}}\right)$ zones were derived from microlog and induction readings using resistivity correction charts (Schlumberger, $1979)$; (2) resistivity of the formation water $\left(R_{\mathrm{w}}\right)$ and that of the mud filtrate $\left(R_{\mathrm{mf}}\right)$ were measured in samples; (3) the sands were assumed to possess a grain volume conductivity and a clay coating structure according to the model proposed by de Lima and Sharma (1990). Kaolinite has been shown to be the dominant clay in the shaly shell sands (for which $\left.\sigma_{\mathrm{sh}}=0.78 \mathrm{mS} / \mathrm{cm}\right)$ and we took the cementation exponent in Archie's equation $\left(F=\phi^{-\mathrm{m}}\right)$ as equal to 2 . Thus, we found from PLD-1 logs sand porosities in the range of 22-25\% and clay volume fractions of $14-16 \%$. Well NCB-1 yielded porosities around $16 \%$ and kaolinite content between 12 and $20 \%$.

Within the S. Sebastião Formation, the high resistivity contrast between sandstones and shales makes it easy to position their limits on electrical logs. Sand bodies of more than $20 \mathrm{~m}$ in thickness may have great lateral extent. Their basal and median zones are uni- 


\section{PLD-1}

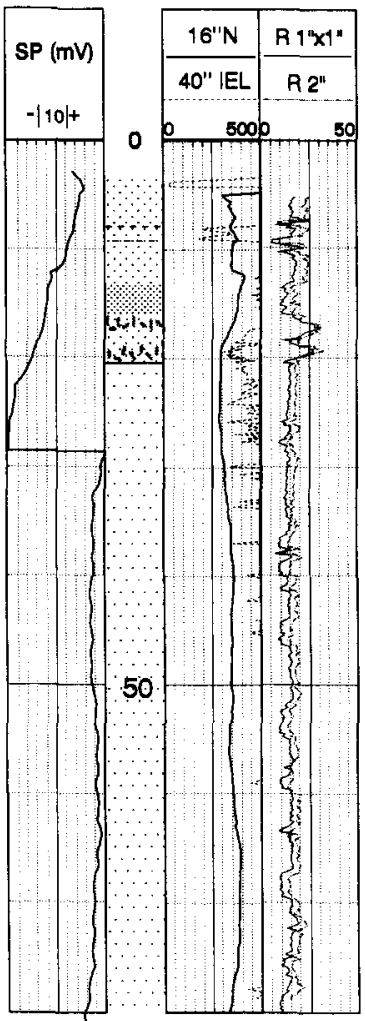

CRB-3

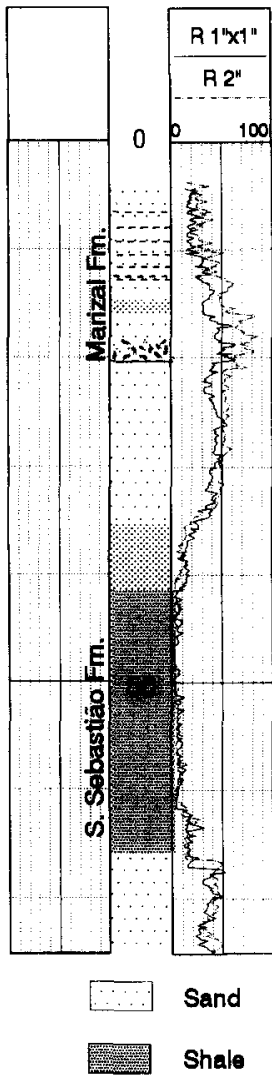

NCB-1

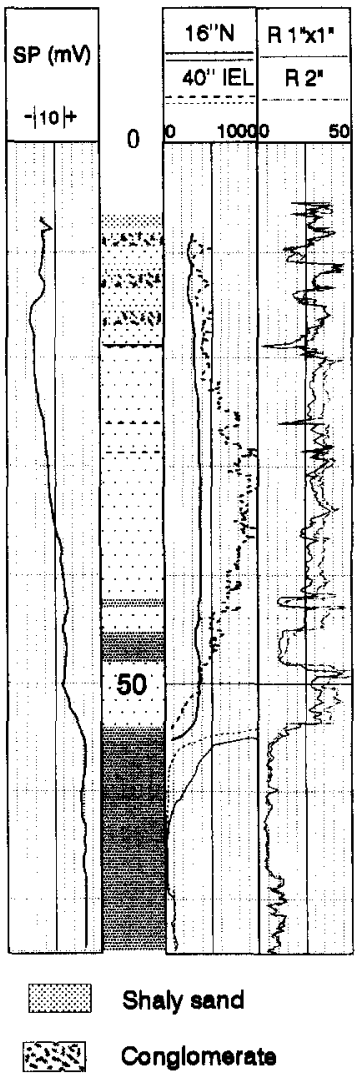

Fig. 4. Geophysical and lithological logs of wells PLD-1, CRB-3 and NCB-1 (see Fig. 1 for location). Apparent resistivity curves scaled in $\mathrm{Ohm} \cdot \mathrm{m}$.

formly fine to medium grained, with an upward fining and increase in clay content in transition to the overlying shales. These textural gradations are well depicted on the SP and resistivity logs as sharp basal discontinuities, followed by straight levels and transitional ramps toward the shale values.
These two formations comprise a fairly complex aquifer system. The Marizal Formation is a water-table aquifer of limited productivity due to its small thickness, poor selection and abundance of aquitard levels. This notwithstanding, it plays an important role in controlling the amount of evapotranspiration and natural

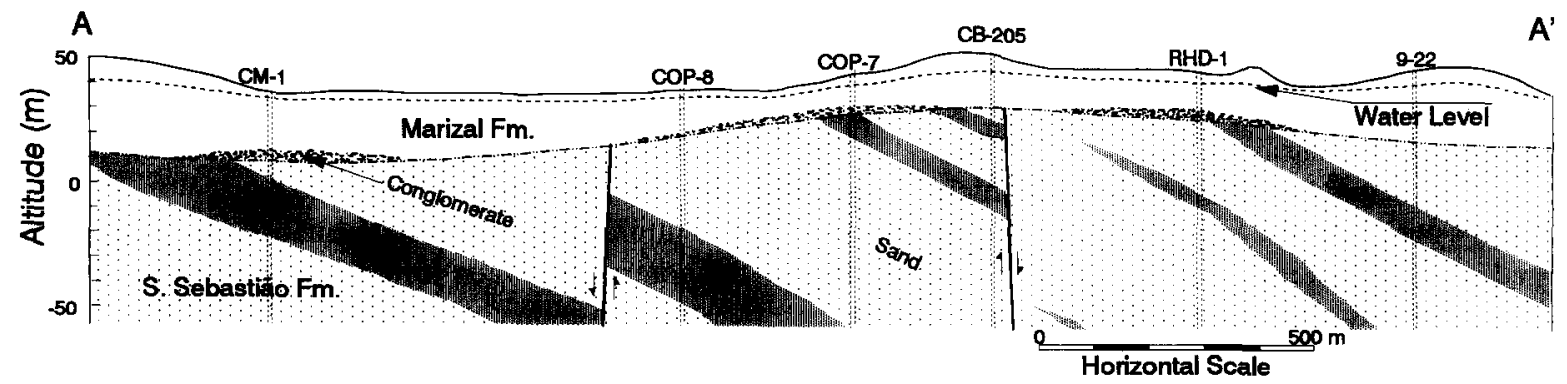

Fig. 5. Geohydrological cross-section through the Copec area (see Fig. 1 for location). The water-level surface is for the S. Sebastião aquifer. 


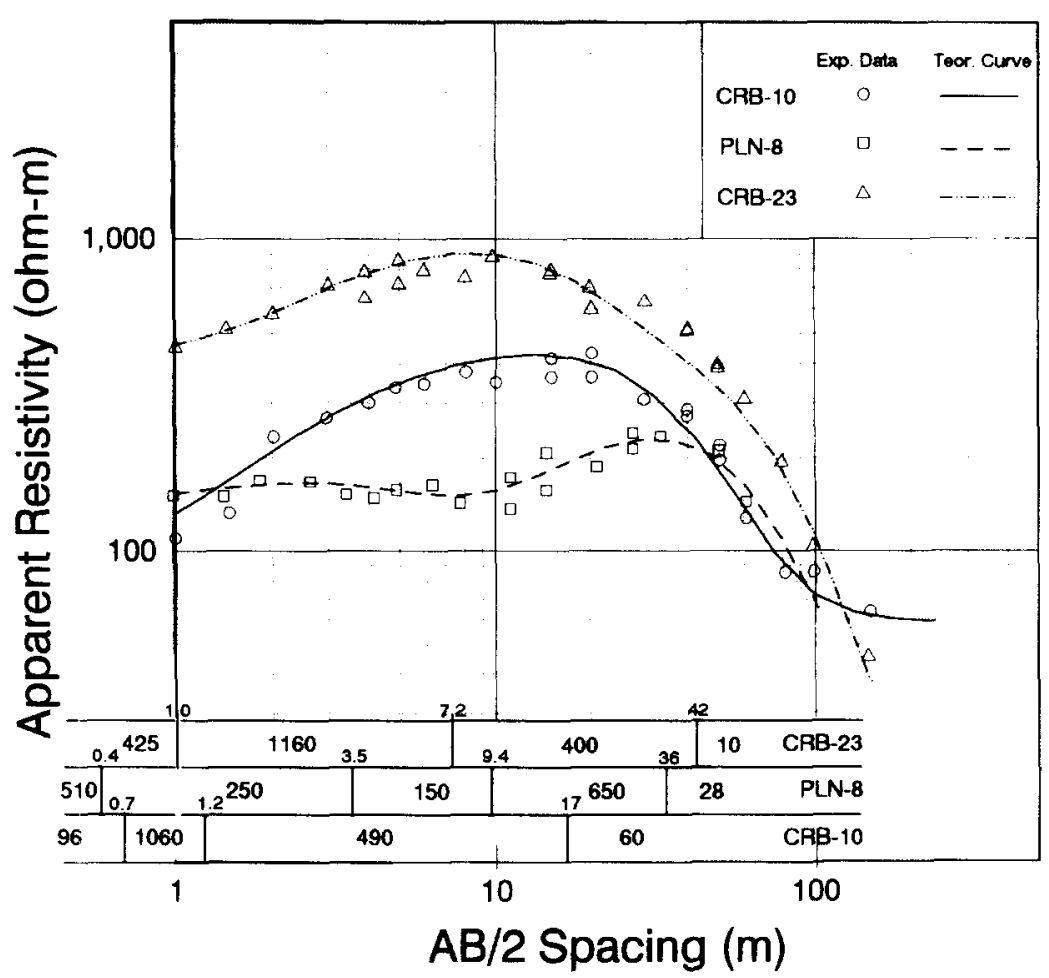

Fig. 6. Typical vertical electrical sounding curves of the area fitted to horizontally layered earth models. Markers show measured data and curves for comparison with the theoretical results.

recharge to the underlying aquifer. Because the lateral continuity of their aquitards were not fully determined, only a partial hydraulic protection of the S. Sebastião aquifer can be assumed in cases of an actual water-table aquifer pollution.

In comparison, the $\mathrm{S}$. Sebastião Formation contains very thick and permeable sands interstratified with shales down to more than $2000 \mathrm{~m}$ deep (de Lima, 1993). Measured porosities and intrinsic permeabilities were within $24.6-32.7 \%$ and $190-5700 \mathrm{mD}$ with averages of $27.5 \%$ and $1870 \mathrm{mD}$, respectively. Fresh, potable waters are abundant down to $1000 \mathrm{~m}$, as interpreted from many SP logs. Some of the shales are very thick and of regional extent. Analysis of temperature logs from wells tapping representative shales allow an estimate of vertical leakage through them at rates ranging from $6.1 \times 10^{-7}$ to $1.2 \times 10^{-6} \mathrm{~cm} / \mathrm{s}$. The sands account for $50-80 \%$ of the total thickness of this formation. The groundwaters are stored under pressure so that they perform as a leaky multi-story artesian aquifer system. Production wells in the depth range from 100 to $300 \mathrm{~m}$ may yield between 50 and $200 \mathrm{~m}^{3} / \mathrm{h}$ of water.
A regional geological cross-section through the Copec area has been constructed on the basis of welllog data (Fig. 5). Groundwater movement within the water-table aquifer is basically controlled by the surface topography so that water levels may outcrop along the surface streams and lagoons in the area. For the artesian aquifer, the regional flow is directed from NW to SE, with a gradient of about 0.005 . A local divergent pattern radiating from the central part of the outcropping area of the Marizal Formation and directed to the major river in the area has been described by de Lima (1993).

\subsection{Data acquisition and interpretation}

Over 45 Schlumberger electrical soundings were made in the studied areas using current electrode separations up to $300 \mathrm{~m}$. Fifteen multiple resistivity profiles were obtained through more than 170 partial soundings at six depth levels corresponding to $A B / 2$ spacings from 5 to $50 \mathrm{~m}$. In addition to this surface geophysical work, electrical logs from 12 water pro- 


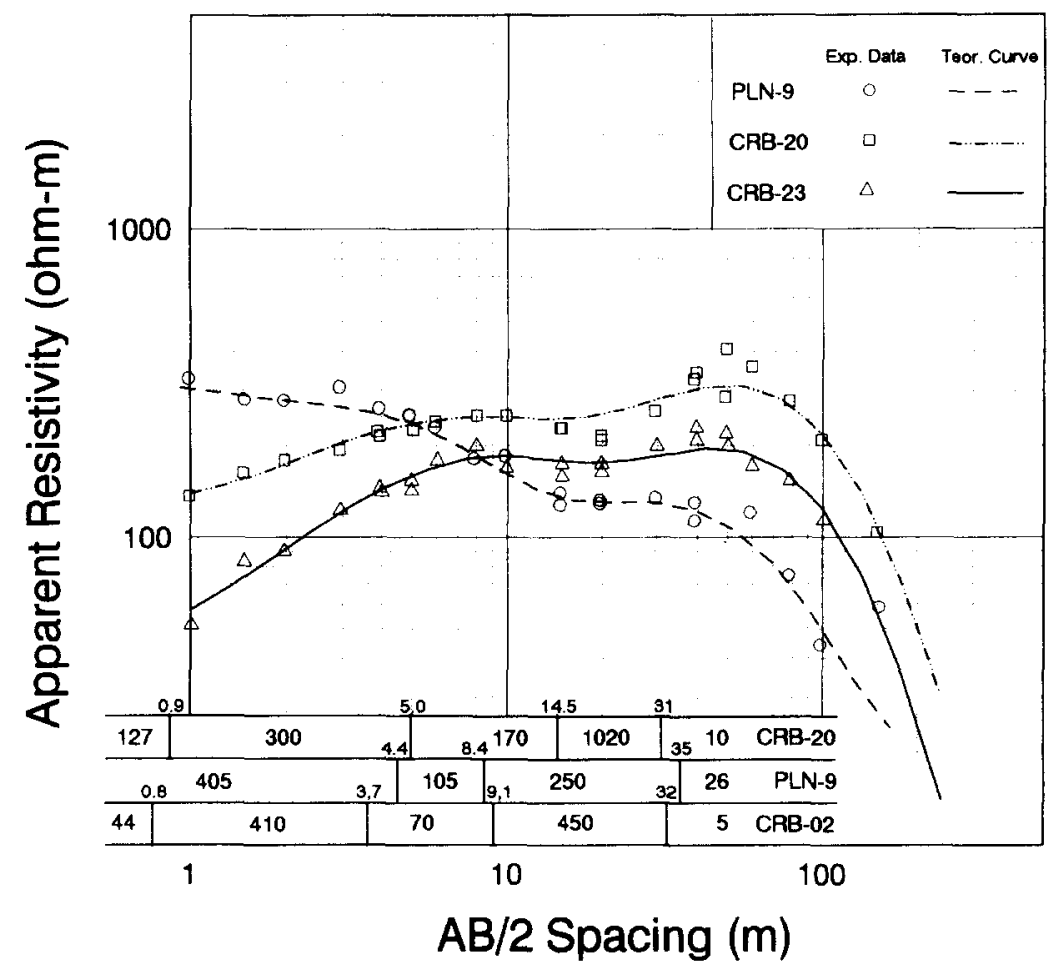

Fig. 7. Typical vertical electrical sounding curves of the area, fitted to horizontally layered earth models. Markers show measured data and curves the theoretical results.

duction wells were also obtained. These normally included a spontaneous potential curve, two microresistivity curves, and one deep induction log. We have also used lithologic logs of several piezometric wells drilled in each area.

The resistivity surveys were performed using an ABEM Terrameter system operating at $4 \mathrm{~Hz}$ with a maximum power of $1 \mathrm{~kW}$. Contact resistance with the ground was reduced by wetting the region around the electrodes with salt water. At the larger spacings, however, current electrode arrays were also used. Partial soundings were measured using two multiple electrode cables having electrical terminals at fixed spacings of $5,10,15,20,30$ and $50 \mathrm{~m}$. The distance between stations along a profile was $50 \mathrm{~m}$.

The areas in the vicinity of the industrial installations have the following general characteristics: (1) the presence of an above-ground network of pipes of various sizes through which flow many products and materials; (2) a complex array of flow controllers and several metallic tanks; (3) a network of ditches and buried pipes related to surface drainage, water distribution, and the site fire protection system. These structures contain conductive and insulating components that may act as noise disturbing the electric measurements in its vicinity. Because of this, we located the sounding centers and current electrodes as far away from such installations as possible. Even so, some soundings show characteristic distortions due to the presence of some unrecorded buried elements.

For quantitative interpretation of the electrical soundings we used an automatic, iterative procedure to invert the observed data in terms of horizontally layered earth models. An integrated software program was developed for personal computer operation. The forward modeling starts with an initial guess obtained from a preliminary interactive interpretation by partial curve matching in the resistivity transform domain as proposed by Koefoed (1979).

In general, the inversion of an electrical sounding involves the following steps: (1) the experimental data obtained as overlapped branches in a discrete Schlumberger sounding are smoothed and re-sampled at equispaced logarithmic intervals using numerical 


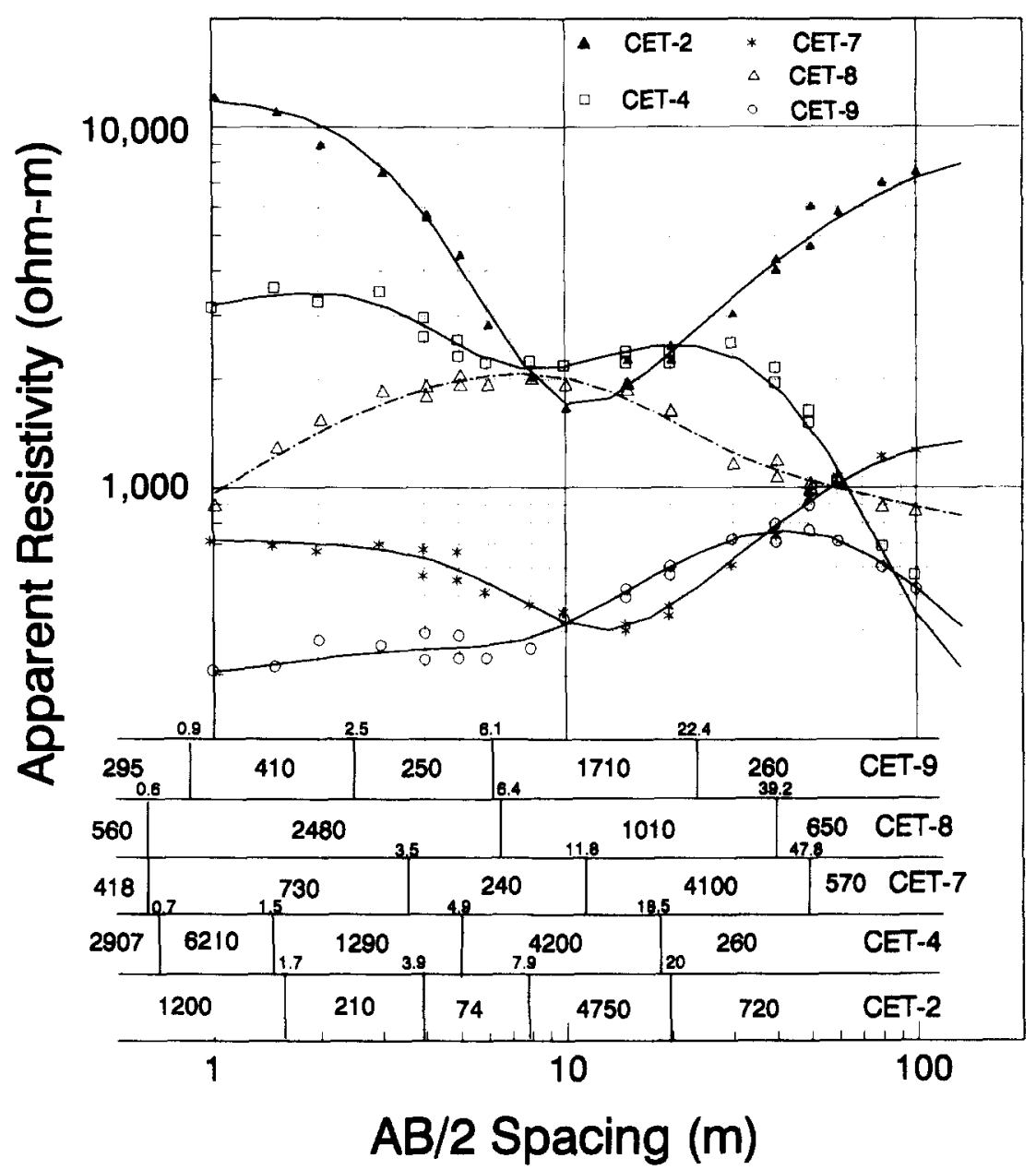

Fig. 8. Typical vertical electrical sounding curves of the area, fitted to horizontally layered earth models. Sounding CET-2 is plotted with apparent resistivity values multiplied by 10 .

interpolation techniques; (2) the re-sampled values are used in a preliminary, interactive interpretation process using partial curve matching in the resistivity transform domain; (3) with this initial model the sounding is inverted using a ridge regression procedure to fit the data in a least-squares sense. The apparent resistivity curve for this best-fit model is then compared with the observed data. In these steps we used the linear filter theory proposed by Ghosh (1971) to evaluate the convolution integrals. Good confidence in the final solutions is warranted by comparing the interpreted results of adjacent soundings and by comparing logs of existing wells with resistivity soundings centered on them.

Apparent resistivity data measured along complete and partial soundings are represented as pseudo-resis- tivity sections and as apparent resistivity maps constructed for selected electrode spacing. On the pseudo-sections, the measurements taken at a given station were assumed to represent sample volumes located directly below the station at a depth equal to the array spacing. These sections were interpreted by visual analysis of resistivity patterns and through the inversion of the associated electrical soundings. Partial soundings were also inverted using the same process. However, because the partial soundings need a high level of interpolation, the confidence in their models is smaller. By correlating adjacent results and by using models of nearby complete soundings and well logs, it was possible to construct an approximate geological structure underlying a given traverse. 


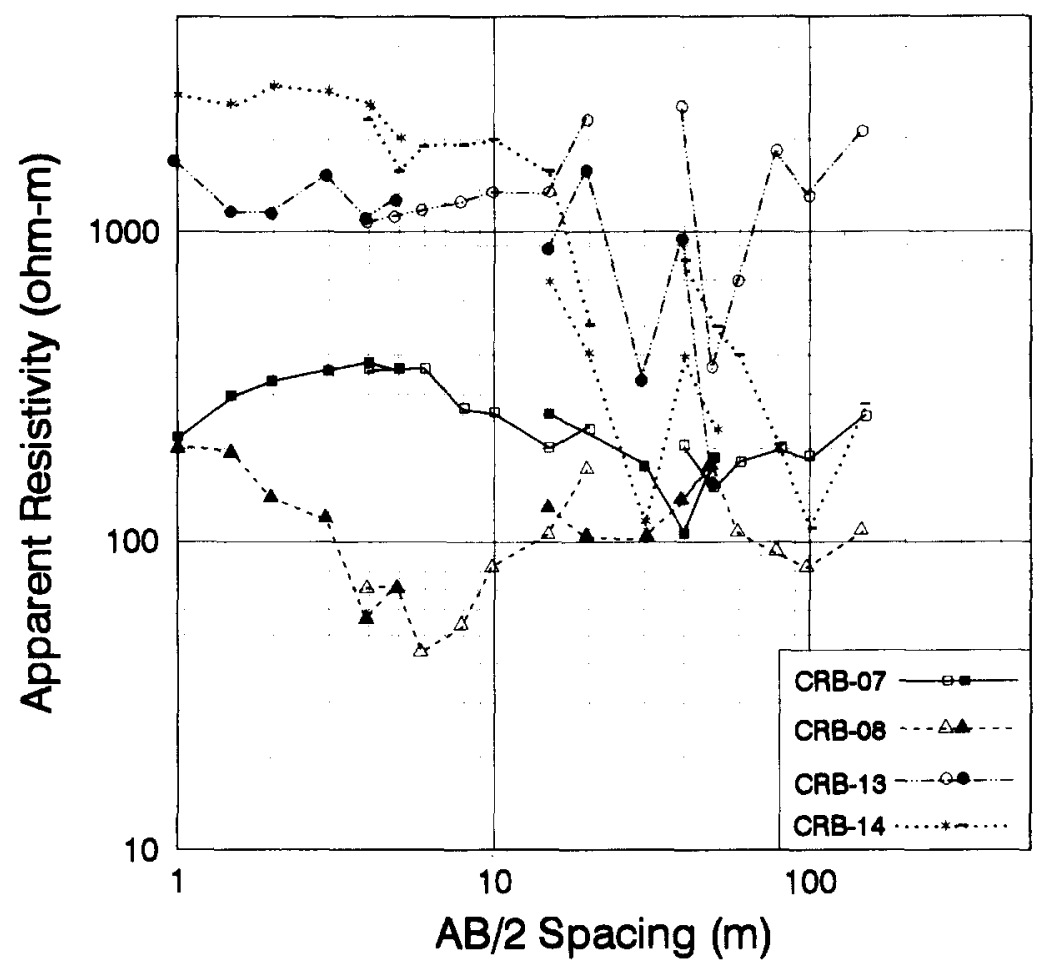

Fig. 9. Sounding curves showing strong lateral effects in the Copec area. Line style and paired markers identifies the soundings.

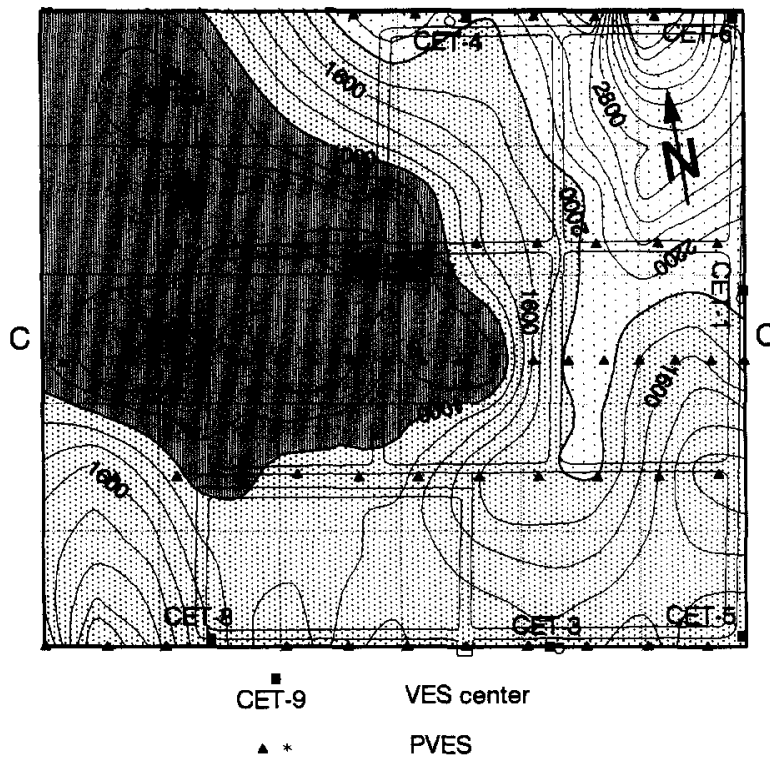

a) $A B / 2=10 \mathrm{~m}$

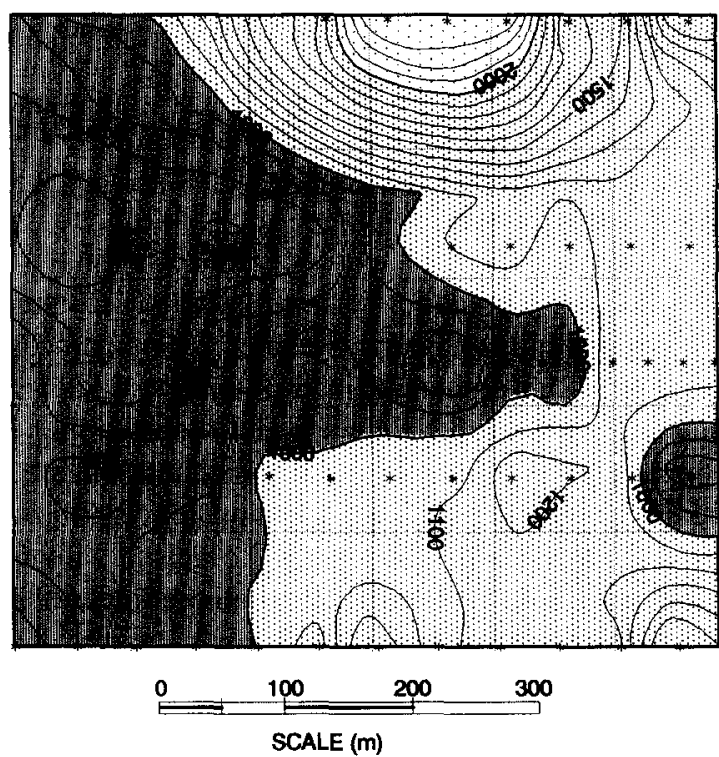

b) $A B / 2=50 m$

Fig. 10. Apparent resistivity maps for $A B / 2$ equal to 10 and $50 \mathrm{~m}$ in the Cetrel area. Most of the actual topography is a plane surface. CET-9 $\mathrm{n}$ a valley dipping to the $\mathrm{NW}$. 


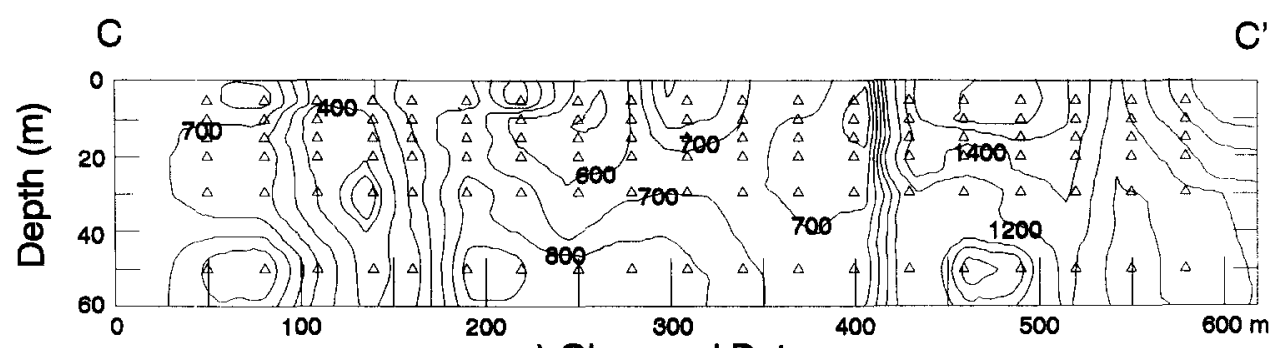

a) Observed Data

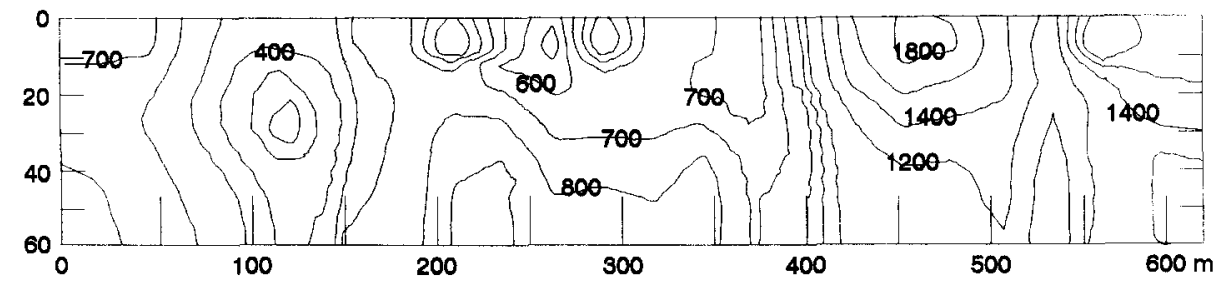

b) Computed 2-D Results

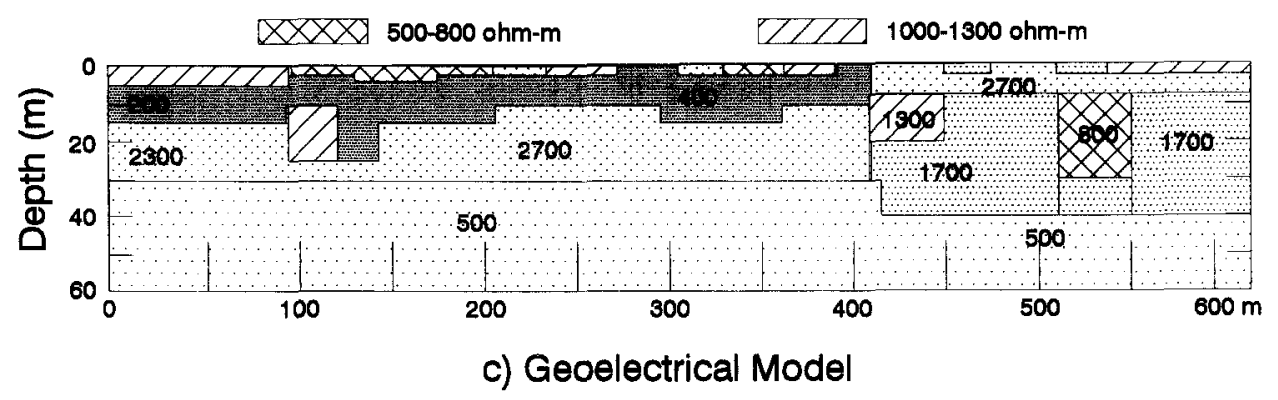

Fig. 11. Pseudo-resistivity section and geoelectrical profile based upon the 2-D interpretation of line $C-C^{\prime}$ in the Cetrel area. $\triangle=$ measured values.

The overall fit of an interpreted structure to a given pseudo-section was estimated using a modified form of Dey and Morrison's ( 1979) finite difference algorithm to compute the electric potential distribution due to point sources of current on a heterogeneous medium having two-dimensional symmetry (Medeiros and de Lima, 1990). At a given step, the computed section is compared point by point with the observed one, and an average quadratic error is computed. If the discrepancies are large, the structure is preferentially modified in its geometry until the average error drops below $10 \%$.

\subsection{Geoelectrical results}

Forty five complete vertical electrical soundings were made in the studied areas (see Fig. 10, Fig. 12 and Fig. 13 for locations). Most soundings are bell- shaped (type K), but there are also variants of composite types like ascending-bell (AK), bell-descending (KQ), and others. The curves are, in general, regular and smooth, attesting to the dominance of sub-horizontal layered structures.

In curves of type $\mathrm{K}$ (soundings CRB-10 and CRB23 in Fig. 6; sounding CET-8 in Fig. 8), the saturated Marizal sands are identified as uniform electrical layers with resistivities ranging from 200 to $1800 \mathrm{Ohm} \cdot \mathrm{m}$. These values are consistent with those observed in the induction logs. The upper limit characterizes areas of clean sands with native freshwaters, whereas the lower limit may be due to the increase in clay content or the presence of conductive contaminants. In the variant $A K$ and KQ curves, the aquifer appears as two electrical levels in superposition, the upper one being less resistive (Fig. 6, sounding CET-9). A more conductive layer may also appear sandwiched in the Marizal aqui- 


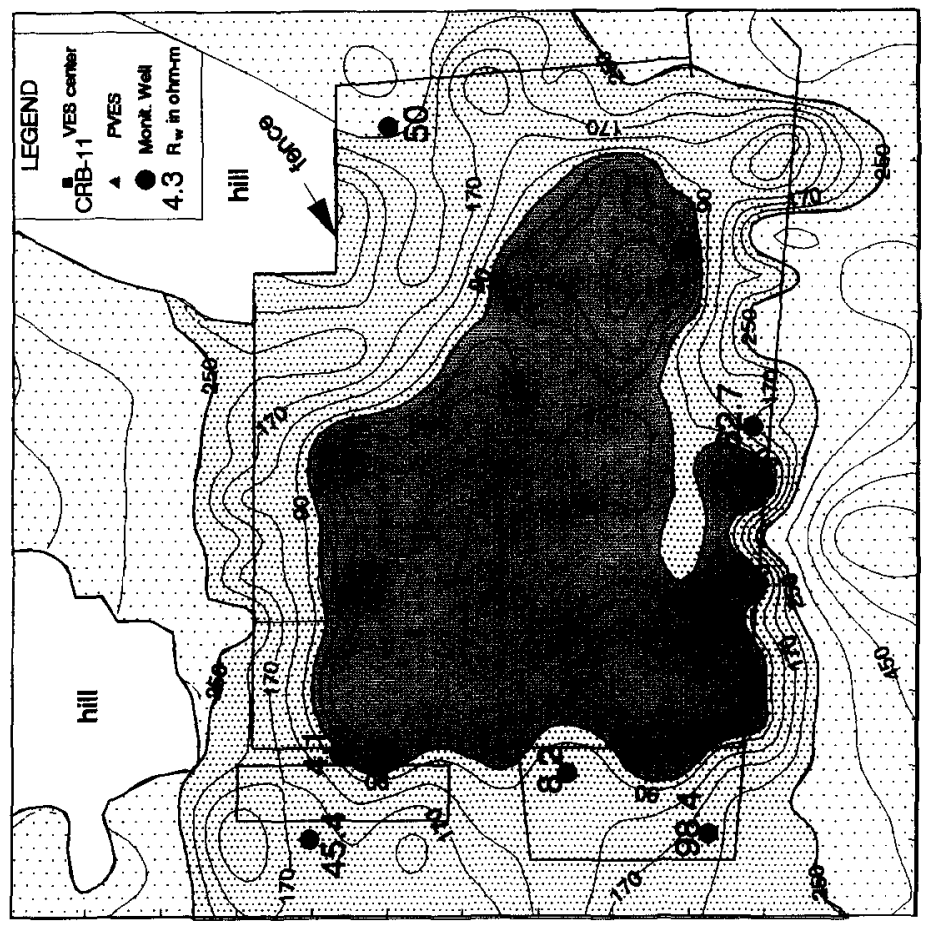

ณ

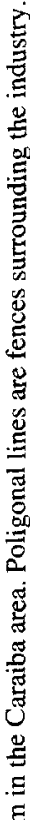

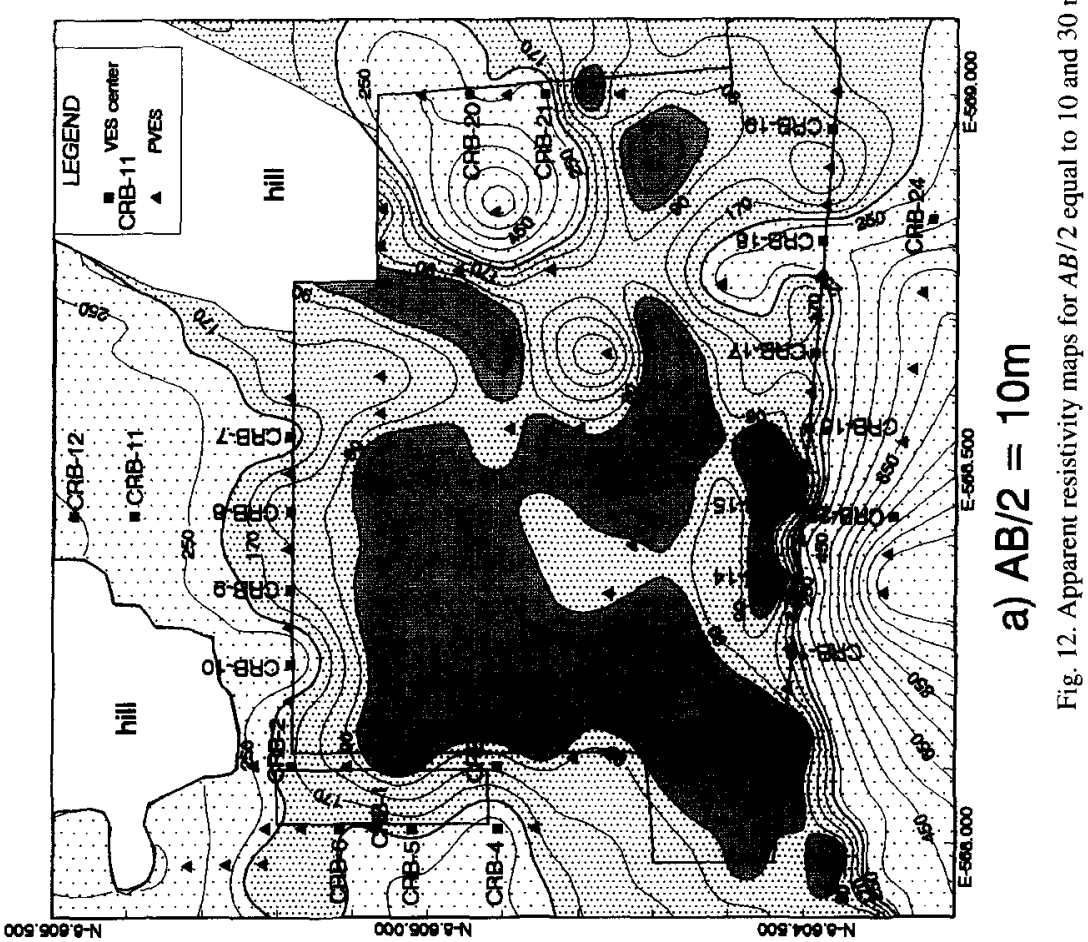


a) $A B / 2=20 \mathrm{~m}$
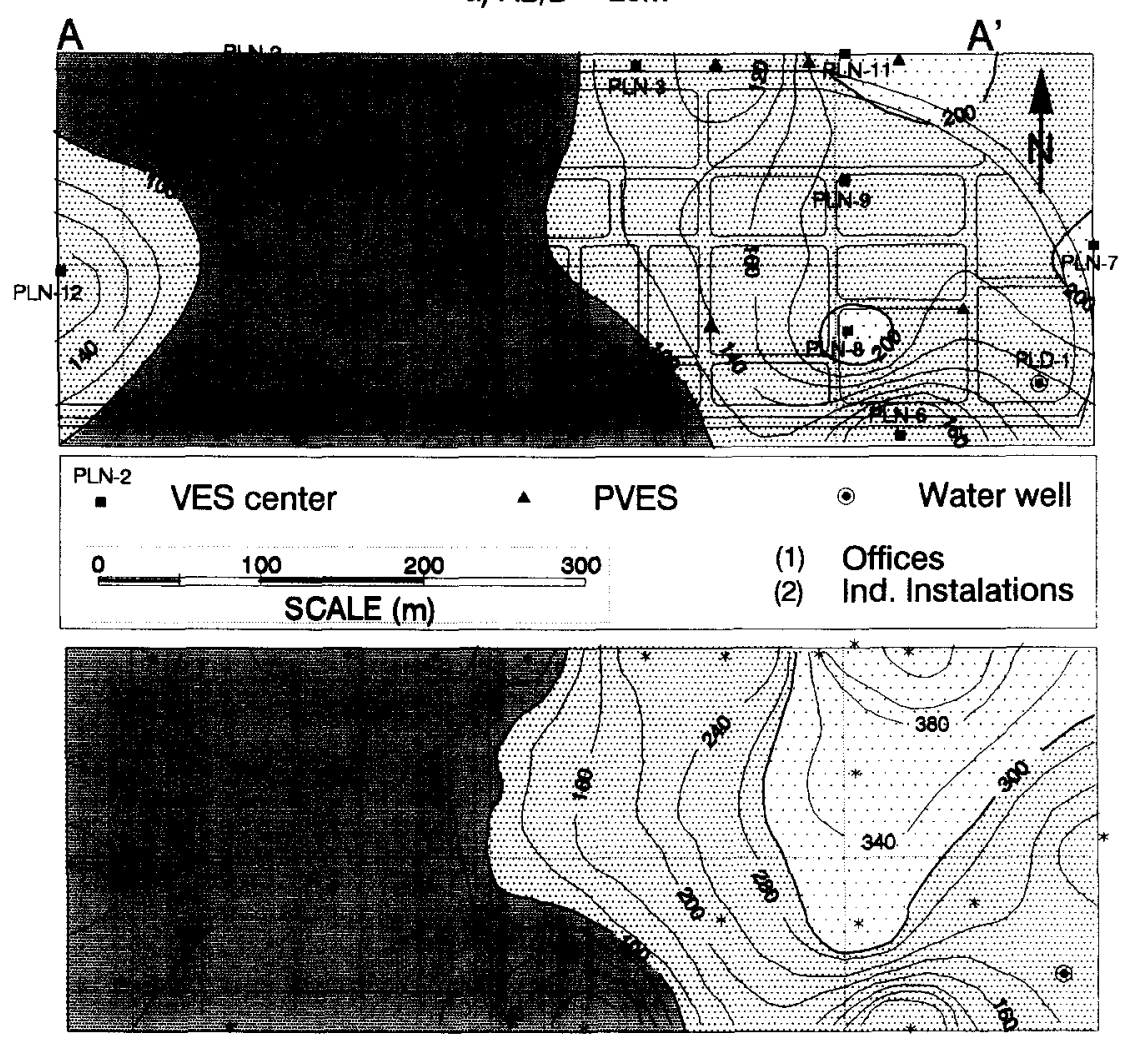

b) $A B / 2=50 m$

Fig. 13. Apparent resistivity map for $A B / 2$ equal to 20 and $50 \mathrm{~m}$ in the Polialden area. The grid on section (a) are roads within the industry.

fer as curves of type KHK (Figs. 7 and 8 ). The resistivity of such a layer may be as low as $20 \mathrm{Ohm} \cdot \mathrm{m}$ and its thickness is interpreted to range from $5 \mathrm{~m}$ to that of the entire aquifer. In all soundings, the underlying $S$. Sebastião is a thick substratum having two characteristic values, one for areas of sand substratum (resistivities of approximately $500 \mathrm{Ohm} \cdot \mathrm{m}$ ) and another for zones of shale substratum (resistivities between 5 and $10 \mathrm{Ohm} \cdot \mathrm{m}$ ). Sounding curves of type KHK are present in the three investigated areas. Their centers are invariably located within or near conductive anomalies outlined on the apparent resistivity maps of these areas, as will be shown later.

Fig. 9 shows examples of sounding curves with sharp distortions clearly related to lateral effects located within the sounding depths. These anomalies are caused by buried structures such as pipes and drainage ditches as, for instance, the Caraiba drainage ditch depicted as a straight linear WSW-ENE anomaly in the map of Fig. 12a.

Apparent resistivity maps for array spacings of 10 and $50 \mathrm{~m}$ obtained around the sludge pits of Cetrel are shown in Fig. 10. These maps show that the high-resistivity unsaturated soil zone increases in thickness toward the NE limit of the area. A strong conducting anomaly is well depicted at all investigated depths in the south-central part of the area. The apparent resistivity contours follow closely the original surface topography, now modified by construction of the sludge pits.

Six $10 \mathrm{~m}$ depth piezometric wells were drilled in the Cetrel area for monitoring leakage from the sludge pits. Lithologic data collected during their drilling have not shown any compositional trends in the Marizal Formation to justify the observed anomaly. Moreover, resistivity measurements of water samples from these wells suggest that the anomaly is related to an increase in water salinity by a factor of 10 in a zone directly 


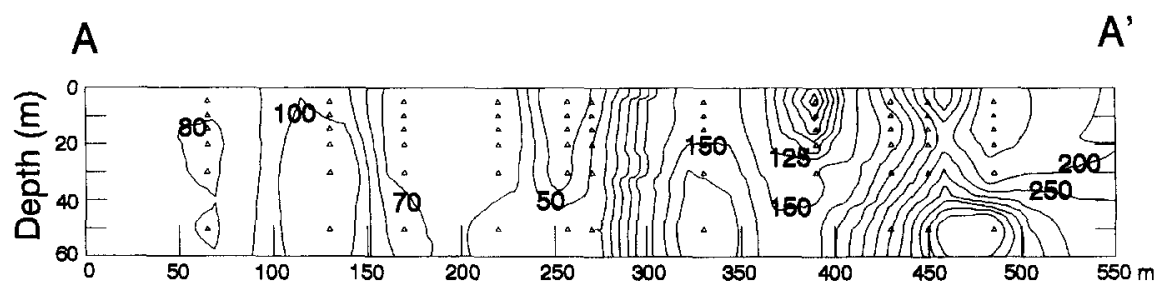

a) Observed Data
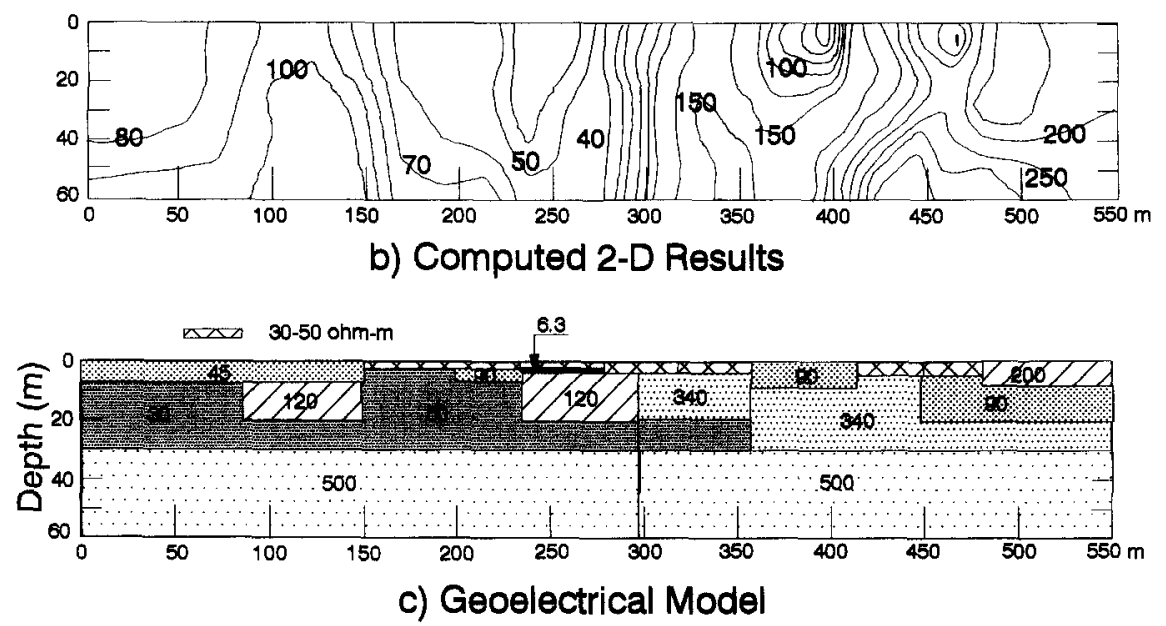

Fig. 14. Pseudo-resistivity section and geoelectrical profile based upon the 2-D interpretation of line $A-A^{\prime}$ in the Polialden area.

below the anomaly. This increase reflects groundwater contamination caused by Cetrel as determined from previous experiments on sludge disposal in the area before the sludge pits were constructed. In these experiments, the process sludges were spread over a series of shallow pits paralleling the contours in an old valley. These trenches are now buried and their inorganic salt content is seeping into the Marizal aquifer.

Fig. 11 presents the observed pseudo-resistivity section, the interpreted geoelectric structure, and the computed two-dimensional pseudo-section for a traverse crossing the center of the Cetrel anomaly (Fig. 10). It can be seen that there are regions in the section where the sub-surface geology is far from a layered Earth model. They are characterized by sub-vertical contours and by strong lateral resistivity gradients. We have treated them as vertical boundaries within the watertable aquifer. The interpreted model also shows the Marizal aquifer resting directly over a thick uniform sand of the S. Sebastião Formation.

Apparent resistivity maps for the Caraiba area are shown in Fig. 12. Again, a remarkable conductive anomaly was depicted on the west-central part of the area. At short spacing $(A B / 2=10 \mathrm{~m})$ the anomaly appears to be caused by different sources. The strongest contrast branch $(\mathrm{N}-\mathrm{S})$ is located around the sulfuric acid plant. It is persistent at all of the measured spacings. The straight WSW-ENE branch is superimposed on the main ditch that drains surface runoff water and all water used in the industry. Soundings CRB-13 and CRB-14 (Fig. 9) were expanded across this underground structure. In the anomalous zone, even the nonsaturated layer has a very small resistivity $(<20$ $\mathrm{Ohm} \cdot \mathrm{m}$ ). The highly resistive areas in these maps are related to thick unsaturated soil covers (at small spacing) and to zones of fresh groundwater (at large spacing).

From electrical sounding data it was possible to show that the N-S anomaly is an extensive body centered below the acid-producing unit and extending downward from the static water level to about $25 \mathrm{~m}$ deep. Its size and shape are controlled by the groundwater movement within the Marizal aquifer. Drilling data from 10 $m$ depth piezometric wells show that the aquifer is almost uniform in the area, but its groundwater shows strong variations in electrical properties. Water resis- 
tivity measurements on samples of these wells are indicated on the map of Fig. 12b. These data not only confirm the geometry of the anomaly but may also explain its amplitude.

Fig. 13 contains apparent resistivity maps for the Polialden area. Once again, a conducting $\mathrm{N}-\mathrm{S}$ anomaly is present on the left side of this industry, at all measured spacings. Apparent resistivities within this zone have magnitudes similar to those in the Caraiba acid plume. In this area, we can also distinguish a more resistive zone on the right side. The surface area above this zone is free from industrial installations, but there are stored barrels of organic solvents, fuels, and other non-aqueous residues (LNAPL).

The pseudo-resistivity section traversing this area and the interpreted two-dimensional geoelectrical structure (Fig. 14) suggest that the lithologic components of the Marizal and S. Sebastião formations are easily identifiable: the first as an upper resistive-conductive succession and the second as a homogeneous substratum of high resistivity. The electrical layering within the Marizal aquifer has a reversed distribution in comparison with that of the Cetrel and Caraiba areas. Here, the top aquifer layer is more resistive. Borehole data also suggest that the conductive anomaly is caused by external sources since it is deep in the area. The resistive body is interpreted to be a top layer partially saturated with LNAPL. During the field work we observed direct hydrocarbon spills on the surface caused by leaks in the storing barrels.

\section{Conclusions}

Some remarkable conductive anomalies were identified within the Marizal aquifer in the area of Copec, Bahia. Lithologic data and geophysical logs of exploration wells allowed us to conclude that these anomalies cannot be explained by the natural compositional changes we have observed in the Marizal formation. There is direct evidence that they result from local increases, both laterally and in depth, in the salinity of the groundwater. Such increases were inferred to be associated with the downward percolation of waters used in the various industrial processes. Normally, such waters become heated and acidified in the processes and thus have increased capacity for dissolved solids.
These geophysical surveys indicate that the S. Sebastião aquifer may be partially protected, at intermediate depths, by some of its semi-pervious shales as well as by the basal conglomerates of the Marizal Formation. In the Caraiba area, for instance, the S. Sebastião substratum is represented by a thick and continuous shale layer bellow the Marizal sequence.

Finally, we summarize the principal merits of the geoelectric technique in comparison with conventional hydrogeological monitoring. The image representations in the form of apparent resistivity maps and resistivity pseudo-sections present a simple but very rich and elegant definition of a contamination plume shape, size, and depth location. An equivalent result obtained by drilling would require a very large number of wells at a cost greater than that of the geophysical survey. Fortunately, the application of shallow geophysical techniques is becoming accepted by the Camaçari petrochemical industries.

\section{Acknowledgements}

The financial support of Financiadora de Estudos e Projetos (FINEP) and the Conselho Nacional de Desenvolvimento Científico e Tecnológico $(\mathrm{CNPq})$ is gratefully acknowledged. Permition to publish these results by the Cetrel, Polialden and Caraiba industries is also recognized and appreciated. We are also grateful to L.M. Santos for invaluable assistance during the field work.

\section{References}

Barker, R.D., 1990. Investigation of groundwater sallinily by geophysical methods. In: S.H. Ward (Editor). Geotechnical and Environmental Geophysics, 2. Soc. Explor. Geophys. Tulsal. OK. pp. 201-211.

Bauman, P., Sallomy, J., Wong. T. and Hardisty, P., 1993. Geophysical data processing techniques as related to groundwater contamination studies. Proc. Symp. Application of Geophysics to Engineering and Environmental Prohlems. EEGS. San Diego. CA. pp. 167-180.

Busseli, G., Barber, C., Davis, G.B. and Salama, R.B.. 1990. Detection of ground water contamination near waste disposali sites with transient electromagnetic and electrical methods. In: S.H. Ward (Editor), Geotechnical and Environmentil Geophysics. 2. Soc. Explor. Geophys., Tulsa. OK. pp. 27-39 
De Lima, O.A., 1993. Geophysical evaluation of sandstone aquifers in the Reconcavo-Tucano Basin, Bahia - Brazil. Geophysics, 58: 1689-1702.

De Lima, O.A.L. and Porsani, M.J., 1992. Geoelectrical monitoring of groundwater contamination in the Camaçari Petrochemical Center, Bahia, Brazil. 62th. Annu. Int. Meet. Soc. Explor. Geophys., New Orleans, LA.

De Lima, O.A.L. and Sharma, M.M., 1990. A grain conductivity approach to shaly sands. Geophysics, 55: 1347-1356.

Deppermann, K., 1955. Die abhängigkeit des scheinbaren widerstandes vom sondenabstand bei der vierpunkt-methode. Geophys. Prospect., 11: 262-273.

Dey, A. and Morrison, H.F., 1979. Resistivity modeling for arbitrarily shaped two-dimensional structures. Geophys. Prospect., 27: 106-136.

Dobecki, T.L. and Romig, P.R., 1985. Geotechnical and groundwater geophysics. Geophysics, 50: 2621-2636.
Ghosh, D.P., 1971. The application of linear filter theory to the direct interpretation of geoelectrical resistivity sounding measurements. Geophys. Prospect., 19: 192-217.

Griffiths, D.H. and Turnbull, J., 1985. A multi-electrode array for resistivity surveying. First Break, 3: 16-20.

Koefoed, O., 1979. Geosounding Principles, 1. Resistivity Sounding Measurements. Elsevier, Amsterdam.

Mazac, O., Landa, I. and Kelly, W.E., 1987. Surface geoelectrics for groundwater pollution and protection studies. J. Hydrol., 93: 277-294.

Mazac, O., Landa, I. and Kelly, W.E., 1989. Surface geoelectrics for groundwater pollution - survey design. J. Hydrol., 111: 163-176.

Medeiros, W.E. and de Lima, O.A.L., 1990. A geoelectrical investigation for groundwater in crystalline terrains of Central Bahia Brazil. Groundwater, 28: 518-523.

Milani, E.J. and Davison, I., 1988. Basement control and transfer tectonics in the Recôncavo-Tucano-Jatobá rift, Northeast Brazil. Tectonophysics, 154: 41-70.

Schlumberger, 1979. Log Interpretation Charts. Schlumberger. 